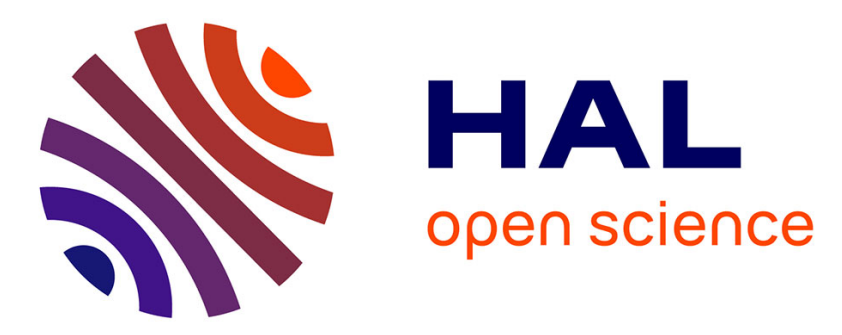

\title{
La parole circulaire du roi. Textes diplomatiques, historiographiques et poétiques (Castille, 1157-1230)
}

\author{
Amaia Arizaleta
}

\section{To cite this version:}

Amaia Arizaleta. La parole circulaire du roi. Textes diplomatiques, historiographiques et poétiques (Castille, 1157-1230). Cahiers d'Etudes Hispaniques Médiévales, 2008, 31, pp.119-133. 10.3406/cehm.2008.1862 . halshs-00472523

\section{HAL Id: halshs-00472523 \\ https://shs.hal.science/halshs-00472523}

Submitted on 1 Oct 2019

HAL is a multi-disciplinary open access archive for the deposit and dissemination of scientific research documents, whether they are published or not. The documents may come from teaching and research institutions in France or abroad, or from public or private research centers.
L'archive ouverte pluridisciplinaire HAL, est destinée au dépôt et à la diffusion de documents scientifiques de niveau recherche, publiés ou non, émanant des établissements d'enseignement et de recherche français ou étrangers, des laboratoires publics ou privés. 


\section{La parole circulaire du roi. Textes diplomatiques,} historiographiques et poétiques (Castille, 1157-1230)

\section{Amaia Arizaleta}

\section{Résumé}

Les documents écrits par la chancellerie castillane entre 1157 et 1230 constituent l'une des voies d'accès à la parole royale. Je m'intéresserai aux mécanismes de construction et de réception de cette parole réinventée dans les diplômes, évoquant également les représentations de l'éloquence des rois dans les textes historiographiques et poétiques contemporains.

\section{Resumen}

Los documentos escritos por la cancillería castellana entre 1157 y 1230 constituyen una de las vías de acceso a la palabra del rey. Estudiaré los mecanismos de construcción y de recepción de dicha palabra, reinventada en los diplomas, deteniéndome también en algunas representaciones de la elocuencia de los reyes en los textos historiográfi cos y poéticos contemporáneos.

\section{Citer ce document / Cite this document :}

Arizaleta Amaia. La parole circulaire du roi. Textes diplomatiques, historiographiques et poétiques (Castille, 1157-1230). In: Cahiers d'études hispaniques médiévales. №31, 2008. pp. 119-133;

doi : https://doi.org/10.3406/cehm.2008.1862

https://www.persee.fr/doc/cehm_0396-9045_2008_num_31_1_1862

Fichier pdf généré le 26/03/2019 


\title{
La parole circulaire du roi. Textes diplomatiques, historiographiques et poétiques (Castille, 1157-1230)
}

\author{
Amaia ARIZALETA \\ Université Toulouse II \\ FRAMESPA (UMR 5136, GNRS) \\ Pour Sophie Hirel-Wouts, en gage d'amitié.
}

\begin{abstract}
RÉSUMÉ
Les documents écrits par la chancellerie castillane entre 1157 et 1230 constituent l'une des voies d'accès à la parole royale. Je m'intéresserai aux mécanismes de construction et de réception de cette parole réinventée dans les diplômes, évoquant également les représentations de l'éloquence des rois dans les textes historiographiques et poétiques contemporains.

\section{RESUMEN}

Los documentos escritos por la cancillería castellana entre 1157 y 1230 constituyen una de las vías de acceso a la palabra del rey. Estudiaré los mecanismos de construcción y de recepción de dicha palabra, reinventada en los diplomas, deteniéndome también en algunas representaciones de la elocuencia de los reyes en los textos historiográficos y poéticos contemporáneos.
\end{abstract}

Les textes composés au Moyen Âge par les scribes du roi sont des produits sociaux - est-il besoin de rappeler que le texte est fait pour être consommé et, par là, pour imprégner le monde auquel il imposera son ordre -, et ce sont, avant tout, des moyens de communication, « des manifestations scripturaires d'un acte de parole $»^{1}$. Bien que l'on puisse estimer qu'ils ne résultèrent pas toujours d'un dialogue à plusieurs voix entre le souverain et

1. Paul ZuMTHOR, «Intertextualité et mouvance », Littérature, 41, Paris : Armand Colin, 1981, p. 8-16, p. 8. 
ses vassaux, le souverain et sa cour et, singulièrement, entre le souverain et son chancelier (ou notaire), les documents du corpus diplomatique se placent dans l'espace de la construction d'un système de pouvoir, dont ils sont de très solides colonnes. On lit dans la Chronica naiarensis que

[...] les hommes, sachant qu'ils pouvaient périr par le feu ou par l'eau, écrivirent leurs connaissances sur deux colonnes faites de brique et de pierre, afin que ne fût pas effacé de leur mémoire ce qu'ils avaient trouvé à force de discernement ${ }^{2}$.

Le support des diplômes de la chancellerie royale était le parchemin, non pas la brique ou la pierre mais, tout comme les hommes d'avant le déluge, les scribes savaient qu'ils devaient consigner par écrit les faits et les paroles mémorables de leurs rois, afin d'en fabriquer des objets (textuels, cette fois-ci) qui résisteraient à la morsure du temps. C'est au texte diplomatique dans sa matérialité même que je m'intéresse : non à sa surface, ou aux sceaux dont il se pare, mais à sa concrétisation comme forme individualisée d'écriture. La forme lui est essentielle ; elle seule peut lui conférer validité ${ }^{3}$. Mon raisonnement se fonde sur les prémisses suivantes : les documents écrits par la chancellerie castillane, entre 1157 et 1230, sont des fabriques de sens, dont le protagoniste principal est le monarque et dont l'édifice formel est susceptible d'être traité comme celui de tout autre texte élaboré avec artifice. Je suivrai donc l'une des voies d'accès à la parole royale proposées par Stéphane Péquignot ${ }^{4}$, m’intéressant aux mécanismes de construction et de réception de cette parole réinventée dans les diplômes, évoquant également les représentations de l'éloquence des rois dans les textes historiographiques et poétiques contemporains ${ }^{5}$.

2. Juan A. Estévez SolÁ (éd.), Chronica naierensis, Turnhout : Brepols, 1995, p. 6 : « [...] scientes illi homines quod aut igne aut aquis perire poterant, in duabus columpnis ex latere et lapide factis studia sua conscripserunt, ne memoria delerentur que sapienter inuenerant ».

3. Olivier Guyotjeannin, Jacques Pycke et Benoît Michel Tock, Diplomatique médiévale, Paris : Brepols (L'atelier du médiéviste, 2), 1993, p. 15, définissent la diplomatique (d'après le Vocabulaire international de diplomatique) comme « la science des actes écrits, où se trouvent consignés soit l'accomplissement d'un acte juridique, soit l'existence d'un fait juridique, soit encore éventuellement un fait quelconque dès lors que l'écrit est rédigé dans une certaine forme propre à lui donner validité ».

4. Stéphane PÉQUignOT, «Introduction. La parole des rois à la fin du Moyen Âge : les voies d'une enquête », e-Spania, 4, décembre 2007, [en ligne], mis en ligne le 26 janvier 2008. URL : http://e-spania.revues.org/document1233.html. Consulté le 7 juin 2008. Pour une vision d'ensemble de la question ici traitée, on se référera aux actes de la première table ronde sur « La parole des rois (couronne d'Aragon, royaume de Castille, XIII $-\mathrm{XV}^{\mathrm{e}}$ siècles) », organisée par le SIREM et la Casa de Velázquez sous la coordination de Sophie Hirel-Wouts, Stéphane Péquignot et François Foronda en juin 2006 dans e-Spania, 4, décembre 2007, http:// e-spania.revues.org/

5. Celle-ci est la version abrégée d'un des chapitres de ma monographie Les clercs au palais. Chancellerie et écriture du pouvoir royal (Castille, 1157-1230), à paraître. 
Il s’agira ici uniquement de résumer les résultats d'une étude portant sur un corpus bâti à partir des chartes issues des chancelleries des rois castillans Sanche III (1157-1158), Alphonse VIII (1158-1214), Henri I ${ }^{\text {er }}$ (12141217) et Ferdinand III (1217-1230 $)^{6}$, ainsi que des textes historiographiques et poétiques composés au royaume de Castille et León au tournant des XII $^{\mathrm{e}}$ et XIII ${ }^{\mathrm{e}}$ siècles, tels que, entre autres, la Chronica regum Castellae, œuvre de Jean d'Osma, chancelier de Ferdinand III, l'Historia de rebus Hispaniae, écrite par Rodrigue Jiménez de Rada, grand chancelier d'Alphonse VIII et archevêque de Tolède, le Chronicon mundi de Luc de Tuy, et les deux poèmes anonymes Poème de Benevívere (ou Vita Didaci) ${ }^{7}$ et le Libro de Alexandre qui pourraient (mais ce n'est pour l'instant qu'une hypothèse) avoir été composés dans le cercle d'influence de la chancellerie ${ }^{8}$.

\section{Un discours pragmatique}

On lit dans un travail récent sur les chancelleries médiévales :

Las informaciones de que disponemos para conocer el proceso genético de la documentación no son muy abundantes. Dada la movilidad del monarca, su natural generoso, su propensión a las liberalidades y las necesidades a las que se vio sometido a lo largo de su agitado reinado, hay que pensar que fueron muchas las ocasiones en que peticionarios de toda condición, especialmente eclesiásticos, solicitaron favores del soberano; y que no menores fueron las de los nobles

6. Julio GONZÁLEZ, El reino de Castilla en la época de Alfonso VIII, 3 vol., Madrid : CSIC, 1960 ; id., Reinado y diplomas de Fernando III, 3 vol., Cordoue : Publicaciones del Monte de Piedad y Caja de Ahorros de Córdoba, 1983-1986. Julio González n'a pas édité tous les documents confirmés par les monarques castillans, et bon nombre des diplômes ne sont arrivés jusqu'à nous que sous forme de copies tardives. Voir María Soledad ARRIBas GonzÁLEz et Rosa María GARCía CALVO, «Fuentes para el reinado de Alfonso VIII en el Archivo de la real chancillería de Valladolid », in : J. NUÑO GONZÁLEZ (coord.), II curso de cultura medieval. Aguilar de Campoo, 1-6 octubre 1990. Seminario : Alfonso VIII y su época, Aguilar de Campoo : Centro de estudios del románico, 1992, p. 379-386 ; Pilar OsTos SALCEDO, « La cancillería de Fernando III, rey de Castilla (1217-1230). Una aproximación », Archivo hispalense, 56, 1994, p. 59-70 ; id., « La cancillería de Alfonso VIII, rey de Castilla (1158-1214) : una aproximación », Boletín Millares Carlo, 13, 1994, p. 101-136. Les erreurs de l'édition de González sont par ailleurs abondantes : voir M. Josefa SANZ FUENTES, « Cancillería y cultura : los preámbulos en la documentación de Alfonso VIII », in : J. NuÑo GONZÁLEZ (coord.), II curso de cultura medieval. Aguilar de Campoo..., p. 387-390. Maurilio PÉREZ GONZÁLEZ, El latín de la cancillería castellana (1158-1214), Salamanque-Léon : Ediciones Universidad de Salamanca - Ediciones Universidad de León, 1985 et « Sobre la edición de textos latinos medievales : la carta de Alfonso VIII a Inocencio III en 1212 », Veleia: Revista de prehistoria, historia antigua, arqueología y filología clásicas, 17, 2000, p. 231-266, a comblé en grande partie les lacunes de l'édition de J. GONZÁLEZ, El reino de Castilla...

7. Voir Estrella Pérez Rodríguez, Vita Didaci. Poema sobre el fundador de Benevívere, Léon : Université de León, 2008.

8. Voir A. ARIZALETA, Les clercs au palais... et id., «El Libro de Alexandre : el clérigo al servicio del rey ", Troianalexandrina. Anuario sobre Literatura Medieval de Materia Clásica, 8, à paraître. 
y vasallos villanos que, directa o indirectamente, impetraron el pago de los servicios prestados, en especial los militares, mediante concesiones territoriales o privilegios ${ }^{9}$.

Le souverain dont il est ici question est Ferdinand II de León (11371188, mais la citation aurait pu évoquer le processus génétique de tout document émis par les rois hispaniques qui régnèrent au cours du Moyen Âge central : la demande des vassaux des monarques était effectivement à l'origine des diplômes royaux, que ce fût au León, en Castille ou ailleurs. C'était cette demande-là qui motivait la parole du roi et, par conséquent, l'écriture des textes ; ces demandeurs de textes assistaient à la lecture des documents et participaient à leur authentification.

Le diplôme de chancellerie est fonctionnel, sa nature est juridique mais aussi sociale et politique. Le document est un instrument public ; il «devient », grâce à la solennité de sa présentation en sociétée ${ }^{10}$. Le texte documentaire existe par l'écriture, mais aussi par la lecture : il n'est promulgué, donc vérifié, que lorsqu'il est lu devant un auditoire. De ce fait, il se situe dans une position doublement médiane : il agit dans la relation existante entre le monarque et ses vassaux, certes, mais se place aussi au niveau des liens entre l'auteur de l'action juridique, c'est-à-dire le souverain, et l'auteur du document écrit, c'est-à-dire un membre de la chancellerie royale. Ce n'est pas tout : il se range également entre son lecteur et son public. La dépendance entre auteur, scribe, émetteur vocal et récepteur, caractéristique de la période antérieure à l'invention de l'imprimerie, est singulièrement visible dans le cas des documents de la chancellerie ; ce qu'on a pu désigner comme étant une « instance créatrice multiple » semble bien être d'actualité dans le présent travail ${ }^{11}$. Clercs, moines, nobles, chevaliers des ordres militaires ou vecinos des villes interprétaient les chartes. Ils en déchiffraient les signes. La relation existante entre émetteurs et destinataires des documents de la chancellerie peut donc être bel et bien qualifiée de pragmatique : les textes sont objets de communication, adaptés aux attentes des destinataires. Fernando Gómez Redondo l'a bien dit :

9. Manuel Lucas Álvarez, "Las cancillerías reales », in : José Fernández Catón (dir.), El reino de León en la alta Edad Media. V, Léon : Centro de estudios e investigación San Isidoro, Caja España de Inversiones, Caja de Ahorros y Monte de Piedad, Archivo histórico diocesano, 1993, p. 317-574, p. 333.

10. Voir à ce sujet Julio EscalONA, « Lucha política y escritura. Falsedad y autenticidad documental en el conflicto entre el Monasterio de Santo Domingo y el burgo de Silos (ss. XIIIXIV) ", in : José Ignacio de la IGLESIA DUARTE (coord.), Conflictos sociales, políticos e intelectuales en la España de los siglos XIV y XV. Actas de la XIV semana de estudios medievales de Nájera, Logroño : Instituto de estudios riojanos, 2003, p. 205-252 ; Benoît-Michel TocK, Scribes, souscripteurs et témoins dans les actes privés en France (VII - début du XII siècle), Turnhout : Brepols, 2005.

11. Pablo Ancos-García, La forma primaria de difusión y de recepción de la poesía castellana en cuaderna vía del siglo XIII, Madison : UMI Dissertation Services, 2004, p. 29. 
Una obra adquiere una forma (oral o escrita) cuando es requerida por un público, no porque un autor desee dejar constancia de su capacidad creadora. Se compone y se escribe sólo aquello que ha de cantarse y ha de leerse ante un auditorio ${ }^{12}$.

Quoi de plus vrai, en ce qui concerne les documents de la chancellerie ? C'étaient des objets textuels éminemment agissants, qui contenaient l'information de l'action juridique réalisée par des individus qui configuraient en partie l'audience des diplômes. Qui assistait à la lecture des documents de la chancellerie? On peut supposer que les bénéficiaires de la décision royale écoutaient réellement le texte qui ratifiait une donation en leur faveur. Les membres de la curia participaient effectivement aux séances de lecture publique des documents. En effet, la curia regis, que l'on pourrait peut-être qualifier de corps consultatif du roi, dut prendre la forme d'une assemblée présente aux côtés du souverain, composée par la famille du roi, les grands nobles et les grands prélats, ainsi que les officiers du palais ${ }^{13}$. Ces personnes constituaient la curia ordinaire, qui avait donc pour fonction de conseiller le prince dans l'exercice quotidien du gouvernement. Ces ecclésiastiques et ces aristocrates, conjointement avec les fonctionnaires de la cour - parmi lesquels les hommes de la chancellerie - devaient se réunir fréquemment de manière informelle. C'est dans ce contexte que la lecture de la plupart des diplômes du corpus dut avoir lieu. Mais certains textes, qui font part de décisions royales de plus grande portée et qui concernent des questions d'envergure, telles que la paix avec les royaumes voisins ou les contrats de mariage, doivent avoir été lus devant les grandes assemblées - ou curiae extraordinaires - qui avaient traité ces affaires.

Les textes du roi ne touchaient rien de moins que l'administration du royaume et l'exercice de la potestas regia; ils rendaient publiques les sentences du plus haut tribunal de justice de l'État, constitué par la curia dominée par le souverain ${ }^{14}$. Les requêtes des sujets du roi devaient sans doute être formulées de vive voix ; la réponse du roi, souvent consécutive à l'accord et au conseil des hommes de sa cour, avait également un caractère oral. Après être passée par le tamis de l'écriture des clercs de la cour, elle redevenait orale et était représentée devant cette même cour qui avait contribué à la façonner. La réalisation de la parole du monarque semble bien avoir été profondément marquée par ses récepteurs, coauteurs et acteurs du texte et du verbe monarchique. Cette composition en circuit fermé est particulièrement perceptible dans l'espace consacré aux colonnes des

12. Fernando Gómez Redondo, Historia de la prosa medieval castellana. I. La creación del discurso prosístico: el entramado cortesano, Madrid : Cátedra, 1998, p. 10.

13. Voir M. Lucas Álvarez, op. cit.; Evelyn S. Procter, Curia y Cortes en Castilla y Léon (1072-1295), Madrid : Cátedra, 1988 ; L. G. de VAldeavellano, Curso de historia de las instituciones españolas. De los orígenes al final de la Edad Media, 7éd., Madrid : Alianza Editorial, 1998.

14. L. G. de Valdeavellano, op. cit., p. 450. 
confirmants : ceux qui avaient aidé le roi à construire sa volonté signaient le document, immédiatement après la double mention du nom du roi qui commençait à clore le texte ${ }^{15}$.

\section{Langue écrite et réception des diplômes}

La majorité des diplômes des rois castillans entre 1157 et 1230 sont à rattacher à la tradition grammaticale de la latinité tardive. Avec quels critères pouvons-nous analyser la réception de ces textes, caractérisés pour la plupart par le conservatisme de l'écriture, alors que nous savons que le latin écrit traditionnel était le langage de la bureaucratie dans l'Occident médiéval, et qu'il ne correspondait pas à la langue parlée ? ${ }^{16}$ Les auditeurs des diplômes parlaient le romance. Comment résoudre alors l'équation qui se présente à nous? Les documents du roi étaient-ils compris par leur public? Les souverains eux-mêmes comprenaient-ils les textes qui leur revenaient après un voyage circulaire? Accessoirement, les nobles qui fréquentaient les cours royales étaient-ils analphabètes, comme on a l'habitude de le croire ? ${ }^{17}$ Si c'était le cas, nous serions devant une forme de communication verticale, réalisée entre des locuteurs lettrés et des locuteurs illettrés, où les lettrés (les clercs de la chancellerie) posséderaient la maîtrise de la situation. De ce fait, il existerait une frontière entre émetteurs et récepteurs du texte, que seuls certains individus dotés d'une plus grande compétence linguistique, culturelle et sociale réussiraient à franchir ${ }^{18}$.

Si les documents de la chancellerie étaient lus en latin, langue maîtrisée par les clercs mais peut-être pas par les laïcs de la cour, nous pouvons raisonnablement croire qu'ils n'auraient pas été instantanément compris par la plus grande partie des auditeurs. Les monarques, la cour, les bénéficiaires de passage auraient donc dû avoir recours à des traducteurs ou interprètes qui auraient communiqué à leurs auditeurs la teneur essentielle du texte. Il est vrai que le corps des diplômes paraît souvent accessible, ne serait-ce que parce que le lexique employé appartient à la vie de tous les jours. Cela est particulièrement vrai lorsque nous avons affaire à des donations où il importe d'énumérer les terres et les biens concernés : ce

15. J. GonzÁlez, Reinado y diplomas de Fernando III..., p. 514.

16. Geneviève HASENOHR, «Écrire en latin, écrire en roman : réflexions sur la pratique des abréviations dans les manuscrits français des XII ${ }^{e}$ et XIII" siècles », in : Michel BANNIARD (éd.), Langages et peuples d'Europe. Cristallisation des identités romanes et germaniques (VII'-XI' siècle), Toulouse : Méridiennes, 2002, p. 79-110.

17. Francisco Javier HERNÁNDEZ, «Sobre los orígenes del español escrito », Voz y Letra, 10 (2), 1999, p. 133-166, p. 157, sur la réception du traité de Cabreros : «[...] supone una lectura pública y en un lenguaje accesible, pero sólo para los nobles analfabetos presentes a la ceremonia».

18. María del Pilar Álvarez MAURíN, « El registro lingǘstico especial de los documentos notariales medievales », Estudios humanísticos. Filología, 15, 1993, p. 23-39. 
sont précisément ces mêmes énumérations que la scripta et le romance se sont appropriées. Par exemple, on a écrit dans un document de confirmation des possessions du monastère de Valbuena :

[...] concedo locum ipsum in quo prefatum monasterium situm est, cum omnis pertinentiis suis : grangiam de Muriedro, cum omnibus pertinentiis suis quas habet in nemoribus, cum pascuis, molendinis, piscariis et cum egressibus suis ${ }^{19}$.

Même lu dans un latin respectueux de la prosodie classique, cet inventaire devait être tout à fait compris par un auditoire où il y avait des séculiers, tant nobles que paysans ou villanos. La vérité, néanmoins, est que ces textes n'étaient pas lus dans un latin respectueux de la prosodie latine. Je suis intimement persuadée que, comme l'a rappelé Michel Banniard, « les langues romanes ont toujours été écrites, mais en latin $»^{20}$.

Je partage l'avis de ceux qui défendent que la langue parlée commune est consignée par écrit sous un vêtement graphique latin : dans les documents des chancelleries de la période qui nous occupe, seul le vêtement écrit est latin, qui maintient pour l'œil les textes du roi dans la continuité latine $^{21}$. Le latin qu'écoutaient les monarques et leurs courtisans n'en était pas un. Il était lu avec la prosodie du romance ou ibéroroman - langue que d'aucuns nommeraient « castillan archaïsant ». Avant la forme de la scripta, avant la forme du romance écrit, et en même temps qu'elles, la forme du latin, tout en restant traditionnelle, gardait en elle la modernité.

Alors qu'une minorité d'érudits se servait du latin comme langue écrite, tout le reste de la communauté parlait la langue vernaculaire. Celle-ci interférait de manière naturelle dans les pratiques des clercs, même lorsque celles-ci étaient confidentielles, et à plus forte raison lorsqu'il s'agissait de dire l'autorité du souverain. Cela explique, en partie, l'intelligibilité des diplômes. Mais les lettrés revendiquaient la conservation d'un code qui maintiendrait leur identité dans un monde en changement, dans lequel ils

19. J. GonzÁlez, El reino de Castilla..., II, p. 905-907 (doc. 529).

20. Michel BANNIARD, «Genèse de la scripta catalane : entre émergence langagière et mutation féodale », Phrasis, t. 46 (2), 2005, p. 1-20, p. 2.

21. Pour les problèmes liés à la question de la langue de lecture des documents de la chancellerie castillane je me suis inspirée de la sociolinguistique et des travaux (très controversés) de Roger WRIGHT ; voir entre autres son Latín tardío y romance temprano en España y la Francia carolingia, Madrid : Gredos, 1989 ; id., El tratado de Cabreros (1206) : estudio sociofilológico de una reforma ortográfica, Londres: University of London, Queen Mary and Westfield College, 2000 ; id., « La sociofilología y el origen de la primera documentación cancilleresca en forma romance en Castilla », in : Daniel JACOB et Johannes KABATEK (éd.), Lengua medievaly tradiciones discursivas en la Península Ibérica. Descripción gramatical-pragmática, historia-metodología, Francfort-sur-le-Main/ Madrid : Vervuert/Iberoamericana, p. 63-77, 2001 ; id., A Sociophilological Study of Late Latin, Turnhout : Brepols, 2002. J'ai grand plaisir à remercier Michel Banniard d'avoir pris le temps de partager ses points de vue sur ces questions à partir d'un corpus éloigné de sa propre recherche, comme l'est celui que j'étudie ici. Il va de soi que toute erreur est mienne. 
étaient apparus en force ${ }^{22}$, et où ils devaient composer avec de nombreuses nouveautés, dont la réforme de l'orthographe n'était pas la moindre ${ }^{23}$. Dans un tel contexte de négociation culturelle (et politique), où les lettrés devaient maintenir leurs prérogatives tout en cherchant à accéder aux cercles de pouvoir concret, le métier imposait aux écrivains du roi de privilégier une forme codifiée qui marquerait l'éloignement de la communication orale quotidienne. Il leur fallait aussi que la communauté sût qu'ils possédaient la langue de prestige, la langue monumentale. Le latin était encore, au tournant des XII ${ }^{e}$ et XIII ${ }^{e}$ siècles, la langue des rois.

Cependant, le pragmatisme essentiel aux documents de la chancellerie voulait que la diffusion de ces textes eût lieu dans la communication horizontale, où locuteurs et auditeurs partageaient le code linguistique. L'écrivain devait rédiger à l'aide d'un système d'orthographe archaïque, celui du latin classique, qu'il avait appris dans les écoles des cathédrales ; son public exigeait le romance. La solution à ce décalage apparent était de se servir d'un code reconnaissable, celui du latin, mais non crypté. Pour Roger Wright, l'illettrisme n'aurait pas empêché les gens d'avoir accès à la culture lettrée ni à la documentation pratique, puisque la lecture orale établissait un lien entre les non lettrés et le texte écrit ${ }^{24}$.

Dans ce sens, on pourrait envisager que semblable diffusion des documents royaux ait pu donner à voir une apparence d'égalité entre les sujets des souverains. La langue du roi se montrait sous une forme encore intimement liée au pouvoir. Le latin gardait son ascendant, servait à faire exister une cour cosmopolite, et se mettait à portée des vassaux : les documents de la chancellerie étaient vraisemblablement lus à haute voix, avec une prononciation et une morphosyntaxe romanes. N'était latine que la substance de la lettre : l'auditeur savait que cette écriture n'était qu'une

22. Manuel Alejandro Rodríguez DE LA PEÑA, dans «Imago sapientiae: los orígenes del ideal sapiencial medieval », Medievalismo, 7, 1997, p. 11-39, énumère et examine les bases théoriques qui résultèrent, depuis le $\mathrm{XI}^{\mathrm{e}}$ siècle, dans la formation d'un corps social spécialisé, celui des lettrés.

23. R. WRight, El tratado de Cabreros (1206)..., p. 14-17, évoque les particularités de la réforme carolingienne, dont l'objectif était d'assurer l'uniformité des offices ecclésiastiques mais qui avait dressé une barrière entre ceux qui connaissaient le nouveau système et ceux qui l'ignoraient. La nouvelle forme d'écrire en romance sera la réponse à cet obstacle culturel et social. Antonio EMILIANO, « Tradicionalidad y exigencias de realismo en la lengua notarial hispánica (hasta el siglo XIII) », in : Maurilio PÉREZ GONZÁLEZ (coord.), Actas del I congreso nacional de latín medieval (Léon, 1-4 décembre 1993), León : Universidad de León, 1995, p. 511-518, p. 511, l'expose clairement : «Antes del final del siglo XI, más precisamente antes del concilio de Burgos que en 1080 introdujo oficialmente en la Península Ibérica la liturgia romana y con ella el latín medieval reformado, no hay razón para postular la existencia en las comunidades iberorrománicas de una distinción conceptual generalizada y operante entre latín y romance como realidades lingüísticas distintas. La oposición entre latín y romance se estableció definitiva y duraderamente en la Península cerca de dos siglos después, como consecuencia de un proceso dilatado de cambio metalingüístico.»

24. R. WRight, El tratado de Cabreros (1206)..., p. 16-17. 
variante de la langue quotidienne. Le locuteur, écrivain spécialisé, savait manier des correspondances phonétiques et morphologiques qui transformeraient l'orthographe archä̈que en réalité orale contemporaine ${ }^{25}$. Qui plus est, il faut se rendre à l'évidence que : a) tout le texte n'était pas censé être compris par tous les auditeurs. Des parties des documents tels que les préambules ou les formules de malédiction, par exemple, pouvaient ne pas être assimilés par un public qui n'aurait pas prêté toute son attention à la lecture des documents : après tout, une seule partie des diplômes était véritablement capitale, celle du corps du texte ; nous avons vu qu'elle était compréhensible ; b) les jeux rhétoriques des préliminaires appartenaient aux lettrés. Ce furent sans doute les clercs de cour qui apprécièrent le plus les brefs concentrés de style qu'on trouve dans les parties citées ; c) à force d'entendre des variantes souvent infimes d'un même document, les auditeurs intégraient probablement le sens global de la parole royale ; d) il me parait logique d'accepter que, pour certains textes, un traducteur ait pu intervenir pour rendre leur contenu accessible ${ }^{26}$; e) il faut tenir compte du cosmopolitisme de la cour castillane entre 1157 et 1230, accentué par l'arrivée en masse de poètes provençaux après le mariage d'Aliénor Plantagenêt et d'Alphonse VIII ${ }^{27}$ : à la cour on entendait de nombreuses langues, parlées à l'intérieur et à l'extérieur de la péninsule Ibérique. $\mathrm{Ne}$ pourrait-on pas songer que le latin y fonctionnait comme une sorte de koinè, partagée par les hispani et les autres, servant à délimiter la parole et le pouvoir royaux? Le latin cohabitait avec d'autres langues, figurant dans cette polyphonie comme un code à l'apparence étrange, vaguement incompréhensible, mais habituelle et familière, somme toute. Il devait rester apposé aux mains des clercs et aux gestes du souverain. Dans cet univers bariolé, des espaces identitaires restaient à prendre du côté des langues romanes. Elles avaient permis de créer un code spécifique à l'aristocratie, celui de la lyrique courtoise, plurilinguistique, qu'il serait bon d'étudier en corrélation avec le code clérical ${ }^{28}$. Plus tard, le romance allait remplacer

25. Steven N. DwORKIN, «Latín tardío y romance temprano : implicaciones léxicas de una hipótesis controvertida », in : Maurilio PÉREZ GONZÁLEZ (coord.), Actas del I congreso nacional de latín medieval..., p. 489-494, p. 490.

26. R. WRIGHT, op. cit. (passim) est contre cette possibilité. Semblent l'accepter S. DWORKIN, art. cité et A. EMILIANO, art. cité, ainsi que M. BANNIARD, que je remercie encore une fois pour ses mises au point.

27. Vicente BELTRÁn, La corte de Babel. Lenguas, politica y poética en la España del siglo XIII, Madrid : Gredos, 2005, p. 30 : «En Castilla y Léon, sabemos que el matrimonio de Alfonso VIII con otra hija de Leonor de Aquitania produjo un aluvión de poetas provenzales de donde, con cierta seguridad, ha de arrancar toda la tradición cortés, tanto la provenzal como la galaico portuguesa.»

28. V. BeLtrán, op. cit., p. 34 : «[...] la lírica cortés tendía a crear en la élite nobiliaria de los siglos XII y XIII la conciencia de ser un grupo espiritualmente selecto, que así transcendía y justificaba los privilegios inherentes a su posición; el uso de una lengua refinada, a veces la elección de una lengua total o parcialmente ajena, artificial en suma, era uno más de los componentes de este juego literario y social». 
définitivement le latin en tant que code linguistique de la puissance du monarque et du royaume ${ }^{29}$. Par conséquent, la communication entre locuteurs et auditeurs aurait été réelle et le romance aurait retenti dans les palais des rois de Castille, le latin écrit étant un attribut de la puissance des souverains.

\section{Portraits de rois éloquents}

Le partage de l'écriture rapprochait les écrivains des monarques : les uns en avaient besoin pour s'élever dans l'échelle sociale, les autres pour gouverner. Qui plus est, les rois devaient connaître, voire maîtriser, le latin ou, plus pertinemment encore, la langue technique et artistique. Tout comme il ne suffisait pas d'être appelé « clerc » pour l'être vraiment, ceux qui possédaient une compétence active dans le maniement de la langue et de l'interprétation des textes pouvaient être considérés comme étant des clercs, même s'ils ne l'étaient pas. C'est ce que Philippe de Harvengt (abbé prémontré de Bonne-Espérance en Hainaut, 1100-1183) affirmait à la fin du XII siècle :

Vous savez que s'appliquer à la connaissance des Écritures est le propre des clercs, au point que quiconque voudrait devenir clerc doit de toute nécessité être imprégné de savoir littéraire, et que, sans une connaissance au moins minime des lettres, on n'est qu'à peine ou pas du tout considéré comme clerc. Ce qui fait que s'est imposée cette façon de parler : celui que nous voyons lettré, automatiquement nous l'appelons clerc, et puisqu'il s'occupe de ce qui est le propre du clerc, d'office nous lui en assignons le nom. Donc, si quelqu'un compare un chevalier lettré à un prêtre inculte, il proclamera avec assurance et soutiendra sous serment que ce chevalier est meilleur clerc que le prêtre, puisque le chevalier lit, comprend, compose en prose et en vers, et lorsqu'il discourt en latin parmi des clercs, est loué pour ne pas faire du tout de fautes, tandis que le prêtre non seulement ne sait pas mettre en forme sans prêter le flanc aux critiques un discours latin correct, mais ne pourrait peut-être même pas psalmodier tout seul complies selon la règle. Pourtant, ce chevalier que nous disons meilleur clerc que le prêtre, nous savons sans doute aucun qu'il n'est pas clerc : c'est un usage du langage dérivé qui a prévalu, si bien que qui s'adonne aux lettres, ce qui appartient au clerc, est appelé clerc, bien que nul ne doute qu'il n'est pas clerc ${ }^{30}$.

29. Inés Fernández-OrdóÑEZ, «Alfonso el Sabio en la historia del español », in: Rafael Gano Aguilar (coord.), Historia de la lengua española, Barcelone: Ariel, 2004, p. 381-422.

30. Pascale Bourgain et Marie-Clotilde Hubert, Le latin médiéval, Turnhout: Brepols, p. 319 : « Scitis quia dare operam scientie Scripturarum ita est proprium clericorum, ut quicumque voluerit clericus fieri, necesse sit litteris imbuatur, et sine earum quantulacumque scientia, vel vix vel non quisquam clericus habeatur. Unde loquendi usus obtinuit ut quem viderimus litteratum statim clericum nominemus, et quoniam agit quod clerici sit, ex officio ei vocabulum assignemus. Si quis igitur litteratum militem idiote presbytero conferat, fiducialiter exclamabit 
On m’opposera que Philippe de Harvengt n'était pas castillan, que ces considérations-là n'étaient pas pertinentes dans le royaume de Castille. Cela est peut-être vrai ${ }^{31}$. Malgré le doute, les pages qui suivent vont tenter de proposer certains éléments relatifs à l'écriture en chancellerie et à la réception des documents du roi qui suggéreront que, dans la période qui m'occupe, les souverains castillans ainsi que leurs grands courtisans n'étaient peut-être pas des illettrés, et que peut-être ils auraient pu être considérés, non pas comme des clercs mais comme ce « miles » qui « legit » et « intelligit ».

Affirmer que Sanche III, AlphonseVIII, Henri I ${ }^{\mathrm{er}}$ ou Ferdinand III (12171230) étaient des « lettrés » serait sans doute un « usage du langage dérivé » - « improprii sermonis usus », comme disait Philippe. Nonobstant, il serait bon d'accepter l'hypothèse que la monarchie castillane du tournant des XII et XIII ${ }^{\mathrm{e}}$ siècles aurait pu posséder une certaine maîtrise des pratiques scripturales et langagières caractéristiques des lettrés présents à la cour : n'est-il pas vrai que tant Jean d'Osma que Rodrigue Jiménez de Rada déclarèrent dans leurs œuvres historiques qu'Alphonse VIII était « sapiens » et possédait, par conséquent, la « sapientia » ? ${ }^{32}$ Il s'agit là de l'éloge rhétorique du monarque. Cela dit, ne perdons pas de vue que la vertu de la « sapientia » était propre aux clercs lettrés, et que son attribution à l'un des monarques castillans, par deux des grands prélats du temps, est significative de la proximité existante entre ces clercs et leur souverain : les clercs souhaitent projeter sur la figure royale des vertus propres à leur état et leur métier. Toutefois, les relations personnelles de Rodrigue et de Jean avec Alphonse ne suffisent peut-être pas à expliquer un tel portrait royal. Le roi est paré des signes de la clergie : Luc de Tuy décrivait ses confrères Jean d'Osma et Rodrigue Jiménez de Rada comme étant respectivement « sapientissimus » et «sciencia et moribus eruditus » ${ }^{33}$. Le code employé pour représenter

et cum juramento affirmabit eundem militem meliorem presbytero clericum esse, quia scilicet miles legit, intelligit, dictat, versificatur, et inter clericos linguam latina proferens, soloecismi nescius approbatur, presbyter vero non solum nescit orationem grammaticam irreprehensibiliter informare, sed forte nec completorium solus regulariter cantitare. Et tamen militem quem dicimus presbytero meliorem clericum esse, scimus procul dubio clericum non esse, sed improprii sermonis usus ita preualuit ut qui operam dat litteris, quod clerici est, clericus nominetur, quamvis eum non esse clericum nequaquam dubitetur. »

31. Pour ce qui est de l'accès à la culture écrite et de la possibilité de lire des textes en Castille à l'époque qui nous intéresse, l'opinion commune a été bien résumée par P. ANCOSGARCíA, op. cit., p. 5 : «Sin embargo, lo cierto es que resultaría muy interesante poder precisar qué tasa de alfabetización podríamos encontrar en la Castilla de la primera mitad del siglo XIII, no tanto para deducir de ella que la gente capaz de leer iba a recibir de hecho las obra a través de una lectura ocular, sino para poder determinar cuánta gente podría hacerlo en potencia. En vano se van a buscar, a menos de día de hoy, datos mínimamente fiables [...] En la Castilla de la primera mitad del siglo XIII, PUES, no parece aventurado decir que quienes pudieran tener acceso a las obras a través de la lectura ocular constituirían una élite.»

32. Adeline RuCQUOI, "La royauté sous Alphonse VIII de Castille », Cahiers de linguistique hispanique médiévale, Paris : Klincksieck, 23, 2000, p. 215-241.

33. Emma FalQue (éd.), Lucae Tudensis. Chronicon mundi, Turnhout : Brepols, 2003, p. 328 et 334 . 
le monarque, extrait du champ sémantique de la clergie et du savoir, dut être déchiffré par les courtisans - tant laïcs qu'ecclésiastiques - et compris comme étant destiné à associer le souverain au monde des lettrés. Adeline Rucquoi a affirmé que la cour castillane fut le lieu de formation des futurs prélats, qui entretinrent par la suite des liens privilégiés, non seulement avec le roi «magister », mais encore et surtout avec le futur roi, la famille du souverain et les fils de nobles, eux-mêmes élevés à la cour ${ }^{34}$.

Un des quatre monarques cités se détache du portrait de groupe : Alphonse VIII apparaît nettement comme un roi qui s'est intéressé au savoir comme outil de gouvernement ${ }^{35}$. Le grand-père de Ferdinand III aurait effectivement eu une grande part dans la promotion de la vie intellectuelle à Palencia ${ }^{36}$, et il aurait favorisé l'existence d'une école palatine, destinée à l'enseignement des jeunes nobles. Il aurait aussi incarné un avatar possible de l'idéal du roi « sapiens » avant Alphonse X, s'il faut en croire ceux qui écrivirent des histoires de la péninsule dans la première moitié du XIII ${ }^{\mathrm{e}}$ siècle : Rodrigue Jiménez de Rada dans son Historia de rebus Hispaniae, pour qui le souverain castillan est un compendium de «curialitas » et de «sapientia »- on est en droit de se demander si la première résulte de la deuxième ou à l'inverse -, Jean d'Osma qui affirme dans sa Chronica regum castellae qu'Alphonse VIII " potenter et sapienter exercuit usque in finem uite sue ", ou encore Lucas de Tuy qui qualifie le roi de «sapientia magnus » dans son Chronicon mundi ${ }^{37}$.

En Alphonse VIII auraient pu prendre forme concrète deux modèles de représentation du roi « sapiens » : celui qui découlait de la généalogie

34. A. RUCQUOI, art. cité, spécialement p. 218-222.

35. Sur cette question, on peut se référer à Amaia ARIZALETA, «Ut lector agnosceret: discurso y recepción en la obra de Rodrigo Jiménez de Rada », Cahiers de linguistique et de civilisation médiévales, 26, 2003, p. 163-186 ; Peter LINEHAN, History and the Historians of Medieval Spain, Oxford : Clarendon Press, 1993 ; Georges MARTIN, " Noblesse et royauté dans le De rebus Hispaniae (livres 4 à 9) », Cahiers de linguistique et de civilisation médiévales, 26, 2003, p. 101-121, 2003 ; Manuel Alejandro RODRÍGUEZ DE LA PEÑA, «El paradigma de los reyes sabios en el De rebus Hispaniae de Rodrigo Jiménez de Rada », in : M. GonZÁlez JimÉnEz (éd.), Sevilla 1248, Congreso internacional conmemorativo del 750 aniversario de la conquista de la ciudad de Sevilla por Fernando III, Rey de Castilla y Léon, Madrid : fundación Ramón Areces, p. 757-765, 2000 ; id., « De la schola al palatium: las mutaciones del discurso sapiencial en los reinos de León y Castilla (siglos XI-XIII) », Cahiers d'études romanes, 4, 2000, p. 7-43 ; Ana RoDRÍGUEZ LóPEZ, «De rebus Hispaniae frente a la Crónica latina de los reyes de Castilla : virtudes regias y reciprocidad política en Castilla y León en la primera mitad del siglo XIII », Cahiers de linguistique et de civilisation médiévales, Paris : Klincksieck, 26, 2003, p. 133-149 ; A. RUCQUOI, art. cité.

36. Sur ce point, je me permets de renvoyer à A. ARIZALETA, Les clercs au palais...

37. Pour les citations des textes, Luis CHARLO BREA (éd.), Chronica latina regum Castellae, Cadix : Université, 1984, p. 10 ; Juan Fernández VAlverde (éd.), Roderici Ximenï de Rada. Historia de rebus Hispanie sive historia gothica, Turnhout: Brepols, 1987, p. 280. Luc de Tuy ne s'éloigne pas beaucoup de Jean d'Osma pour décrire Alphonse VIII : « Rex Castelle Adefonsus cepit quasi leo fortissimus cum Christianis et Sarracenis regibus in circuitu regni sui consistentibus fortiter et sapienter armis confligere », E. FALQUE, op. cit., p. 321. 
sapientiale des souverains hispaniques et celui adopté par la cour anglonormande, modèle qui aurait pénétré le royaume de Castille grâce au mariage d'Alphonse avec Aliénor Plantagenê $t^{38}$. La figure royale qui s'est matérialisée au tournant des $\mathrm{XII}^{\mathrm{e}}$ et XIII ${ }^{\mathrm{e}}$ siècles, tant dans le domaine textuel que dans celui de l'iconographie, par l'évocation des attributs et vertus d'Alphonse VIII résulterait d'une fusion de deux traditions scripturales de l'image du roi, l'une indigène, l'autre venue d'ailleurs. À la croisée des influences vécues à la cour de Castille réapparaissent des noms comme celui de Philippe de Harvengt, qui dessinait la figure du prince qui possédait les « litterae », ou du grand-père de la reine Aliénor, Geoffroi le Bel, comte d'Anjou, qui lisait l'Epitome rei militari de Vegèce afin d'y trouver des moyens de prendre la place forte de Montreuil-Bellay ; ou celle de Richard Cœur de Lion, dont l'emploi de l'ablatif résout une querelle avec l'archevêque de Cantorbéry ${ }^{39}$. Marié dans une telle famille, issu d'une lignée qui se préoccupait de faire en sorte que les clercs écrivissent les qualités sapientiales des souverains, Alphonse VIII était théoriquement bien placé pour accorder de l'importance au savoir et pour le pratiquer lui-même.

Jean, Luc et Rodrigue gardent le silence quant aux qualités intellectuelles de Sanche III et d'Henri I ${ }^{\text {er }}$; cependant, la formation du jeune fils de l'Empereur est évoquée dans la Chronica Adefonsi imperatoris où il est dit qu'il fut éduqué par Gutierre Fernández de Castro - auquel fut confié également dans un premier temps le petit Alphonse VIII ${ }^{40}$. Dans ce texte il est dit que Sanche III était censé surpasser tous ceux qui l'entourent, ce qui pourrait laisser supposer qu'il reçut une instruction tant soit peu centrée sur le savoir :

Gutierre Fernández ne tarda pas à venir à la guerre; il jouit de la faveur du monarque. Sanche, le fils de notre empereur, lui a été remis dès sa naissance pour être éduqué par lui. Il l'élève avec amour, il veut qu'il surpasse les autres ${ }^{41}$.

Tel père, tel fils. Un témoignage contemporain fait état de l'éloquence d'Alphonse VIII. On lit dans le Poème de Benevivere, possiblement écrit peu

38. Dulce Ocón Alonso, «Alfonso VIII, la llegada de las corrientes artísticas de la corte inglesa y el bizantinismo de la escultura hispana a fines del siglo XII », in : J. NUÑO GONZÁLEZ (coord.), II Curso de cultura medieval..., p. 307-320 ; je me permets de renvoyer aussi à mon « El Libro de Alexandre... ».

39. Martin AureLL, L'empire des Plantagenêt (1154-1224), Paris : Perrin, 2003, p. 108.

40. J. GONZÁLEZ, El reino de Castilla..., vol. I, p. 150-151 et p. 321-324.

41. Florentino CaStro Guisasola (éd. et trad.), Cantar de la Conquista de Almería por Alfonso VII. Un poema hispano-latino del siglo XII, Almería : Instituto de estudios almerienses, 1992, p. 61 : « Tardius ad bellum Guterrius et Fredinandi / Non venit, est Regis quoniam tutamine fretus. / Sancius est, nostri qui filius Imperatoris, / Cum primum natus, huic traditur ille docendus, / Nutrit eum chare, quem vult omnes superare » (il s'agit des vers 266-270 de la partie finale de la Chronica Adefonsi Imperatoris, connue sous le titre de Poème d'Almeria ou Chanson de la conquête d'Almeria). 
avant 1206 par un clerc rompu à l'écriture documentaire ${ }^{42}$, que ce monarque jouissait de la «facundia linguam » et d'un "sermone benignus »" Ces facultés sont illustrées amplement dans le texte, lorsque Alphonse s'adresse pendant une cinquantaine de vers (v. 696-742) aux moines de l'abbaye qui donne son nom au poème; le roi, y est-il dit, tente de consoler les compagnons de Diego Martínez de la mort de ce dernier; le réconfort qu'il leur offre est de nature verbale : «il tenta de les consoler avec ses mots »- « verbis solamen his sibi ferre cupit $»^{44}$. Que cette représentation d'Alphonse comme roi doué pour la parole soit fidèle à la réalité importe moins que le fait qu'elle est fondée sur l'«eloquentia»: Alphonse, par l'intermédiaire d'un texte écrit par un clerc, apparaît comme un roi qui partage les traits distinctifs de la clergie et qui, par conséquent, maitrise la rhétorique. Des qualités et des actions identiques dessinent les divers avatars de la figure royale à cette période, si nous en jugeons par le Libro de Alexandre: dans cet autre poème, Alexandre est «franc'e ardit e de grant sabiençia» ${ }^{45}$; il dit de lui-même qu'il est «retórico [...] fino» car il connaît le «fermoso fablan» ${ }^{46}$. Enfin, il réconforte ses hommes par un discours efficace lors du départ pour l'Asie : on lit que «el rëy Alexandre dávales grant confuerto» ${ }^{47}$. Le roi de parchemin avait, dans la Castille des premières années du XIII ${ }^{e}$ siècle, les vertus élocutives de l'Alphonse VIII décrit par les clercs.

Les clercs qui entourèrent Ferdinand III ne furent pas en reste : Rodrigue, Luc et Jean trouvent en effet des mots explicites pour le petit-fils d'Alphonse : Luc de Tuy reprend l'adverbe "sapienter » (qu'il avait déjà employé pour se référer à Alphonse $)^{48}$, que l'on retrouve, appliqué au monarque, dans les textes de la chancellerie de Jean d'Osma ${ }^{49}$. À l'ombre de son grand-père, Ferdinand III apparait toutefois comme un monarque que les clercs du palais cherchent à représenter comme partageant les vertus intellectuelles d'Alphonse VIII. Ferdinand reprit le flambeau de son aïeul : Rodrigue Jiménez de Rada affirmait qu'il voulut régner comme son grand-père (« aui sui nobilis Aldefonsi ») $)^{50}$; les documents de sa chancellerie rappellèrent l'étroite filiation que l'héritier s'efforçait de proclamer. Par ailleurs,

42. Il faudra revoir ces points à la lumière de la récente étude, très complète, d'E. PÉREZ RoDríguez, Vita Didaci...

43. E. PÉREZ RodríGueZ, op. cit., v. 75 et 77, p. 254.

44. Ibid., v. 696, p. 298.

45. Juan Casas Rigall (éd.), Libro de Alexandre, Madrid : Castalia, 2007, v. 6b, p. 131.

46. Ibid., v. 42 a, p. 144.

47. Ibid., v. 253c, p. 198.

48. Emma FalQue (éd.), Lucae Tudensis. Chronicon mundi..., p. 336 : « Rex autem Castelle Fernandus quam gloriose et quam sapienter se tunc temporis gesserit, non est qui scriptis ostendere possit. »

49. Force est de reconnaître, cependant, que cet adverbe (ici comme dans le texte de Luc) semble moins significatif de la science des rois que de leur capacité de jugement.

50. A. ARIZALetA, «Ut lector agnosceret... », p. 170. 
il est dit dans le Setenario (commandé par Alphonse, fils du dernier et arrière-petit-fils du premier) qu'il avait «muy buena palabra $[. .$.$] en todos sus$ dichos [...] en mostrar su rrazón muy buena e muy conplida a aquellos que la mostraua, mas rretraer aun e departinn ${ }^{51}$. Alphonse X n'oublie pas de mentionner les gens de la cour : son père, dit-il, savait se servir de la raison dans tous les domaines, même dans ceux plus spécifiquement caractérisés par l'action des courtisans - «e en todas las otras cosas que ssabian bien ffazer et vsar los omnes corteses e palaçianos» ${ }^{52}$.

Ces images d'Alphonse VIII et de Ferdinand III correspondent peutêtre à la description réelle de souverains qui avaient accédé à la culture écrite. Une transmission de connaissances aurait donc pu avoir eu lieu véritablement au sein de la famille de ces deux monarques ; cette transmission se serait accomplie à la cour de Castille, où arriva Ferdinand depuis León (et telle généalogie de savoirs aurait pris forme grâce à Bérengère, qui reliait le passé, le présent et le futur pendant le bref règne d'Henri I ${ }^{\text {er }}{ }^{53}$. Alphonse et Ferdinand constituent donc le noyau de la figuration du roi « sapiens », avant la deuxième moitié du XIII ${ }^{\mathrm{e}}$ siècle et l'avènement de leur héritier, Alphonse X.

Que de telles descriptions aient correspondu à une réalité ou plutôt à un désir des clercs de proposer des archétypes compréhensibles et potentiellement imitables à leur destinataire, le souverain - dont la compétence était présupposée et instituée par ces mêmes lettrés -, est une question qui doit être posée. Il est indéniable qu'en Castille et au León ce furent les grands ecclésiastiques qui fournirent les clés de cette modélisation. Beaucoup reste à faire sur les traditions de la représentation royale, notamment en ce qui concerne l'empreinte de la cour Plantagenêt dans les pratiques culturelles des cours castillanes au tournant des XII ${ }^{\mathrm{e}}$ et XIII ${ }^{\mathrm{e}}$ siècles. Cela dit, ce n'était pas mon objectif ici que de me consacrer à une telle recherche. Il fallait plutôt tenter de reconstruire les modalités de production et de réception d'une parole royale orale et nécessairement écrite, puisqu'elle devait faire preuve ; d'une parole circulaire, que le monarque prononçait et que la chancellerie façonnait, lui donnant la forme de mille copeaux, envolés et toujours retournés au palais de la mémoire du roi.

51. Kenneth Vanderford (éd.), Setenario, Madrid : Crítica, 1984, p. 12. Sur ce point, voir Georges MARTIN, "Alphonse X ou la science politique (Septénaire, 1-11)», Cahiers de linguistique hispanique médiévale, 18-19, 1993-1994, p. 79-100, 20, 1995, p. 7-33 ; id., « Datation du Septénaire : rappels et nouvelles considérations ", Cahiers de linguistique et de civilisation hispaniques médiévales, 24, 2001, p. 325-342.

52. K. VANDERFORD, Ibid.

53. Voir par exemple Georges MARTIN, « Berenguela de Castilla (1214-1246) : en el espejo de la historiografía de su época », in : Isabel MORANT (dir.), Historia de las mujeres en España y América latina. I : de la prehistoria a la Edad Media, Madrid : Cátedra, 2005, p. 569-594. 